\title{
Medical System Reforms in China after 1978: Some Practical Implications \\ Jin-Hua WANG \\ ${ }^{1}$ Guanghua School of Management, Peking University, Beijing, China \\ ${ }^{2}$ Weihai City Commercial Bank, Weihai, Shandong \\ email:gracewangjinhua@gmail.com
}

Keywords: Medical reform; Hospitals; Policies; Implications

\begin{abstract}
Since China' Reform and Opening-up, our country experienced several reforms, each of which was closely related to the economic and social development, and this institutional change makes more effects on the medical system. Since 1978, China has implemented a series of reform policies in tandem with the development of the economy. Based on economic system change, this article divided the development of medical reforms into four stages and each has distinct characters, in terms of government investment, coverage of medical insurance, medicine circulation, etc. A point arising is how to reform the medical system at the national level. This paper aims to provide an overview of medical system in China since 1978, and its practical implications.
\end{abstract}

\section{Introduction}

When the Cultural Revolution came to the end, China shifted from isolation to open to the outside and the Chinese government, as an isolationist, began to change politics-oriented policies to economics-oriented policies, which means a shift from planned economy to market economy. In order to accord with the change of political and economic circumstances, medical system was called for reform. Since China' Reform and Opening-up, our country experienced several reforms, each of which was closely related to the economic and social development, and this institutional change makes more effects to the medical system. According to the analysis of the social change and the phases of China's economic system change, this article divided the development of medical reform into four stages, combined with the actual progress of medical reform. At each stage, social circumstances, policy maker and policy issues in healthcare reform were collected as the following shows. Reviewing the past reforms makes Chinese medical system reform clear, and then illuminates the way ahead.

\section{Method}

\section{Data Gathering}

The formal research methods I want to mainly use are the interview and literature review in as much as, for my purposes, the document review actually belongs to the literature review. Each of these methods is discussed below.

Firstly, by reviewing literatures in both Chinese and English, this research hopes to gain evidence for answers to the following questions:

(1)How many documents, promulgated by the national government, related to the reform of medical system?

(2)What are the key documents?

(3) What are the contents of these documents?

In order to gain clarity on these issues, I want to review the policy documents, and other resources, including scholar's writings and dictionaries. In addition, in the process of literature review, I also want to review newspapers and some statistical materials so that an overview can be 
obtained.

Review of policy documents. The policy documents to be reviewed here are not the documents published by the local governments and by the hospitals; rather they are the documents promulgated by the national government since the reform of medical system is a policy of the national government.

There were about 49 documents published after 1978, and all these documents were published either by administrative organizations(e.g. the State Council, the Ministry of Health) or by legislative bodies(e.g. the National People's Congress).Some contents of these documents refer to certain aspects of reform of medical system, and some cover the aspects of medical system reform. Here, I mainly mention some marked documents to illustrate the process of medical reform.

Review of other sources. A total of 80 journal articles and some books relevant to the period from 1978 until now have been reviewed.

Interview. The subjects I have interviewed for this study consist of officials, including the Vice Director of medical reform office of Henan province, the Director of Medical Department of Wuhan city, officials who take charge of special medical of this office; and of some scholars who are well-known in the health care, and who are the consultants of policy making in mainland China. Doctors and nurses working in the hospitals and medical team of the Second Artillery Force and some patients are also interviewed.

By using the methodology of interview, what I hope to discover is:

(1)How and why do they understand the reform of medical system?

(2)What is the status quo and what are the problems of medical system reform in their units?

At least 30 subjects have been interviewed. I have interviewed these subjects during the research process, by using intensive interviews (interviewing several persons in the conference or meeting), informal conversation for the Vice Director of medical reform office of Henan province, a general interview guide approach for some officials and open-ended interviewing for medical servants.

\section{Data Analysis}

The purpose of this phase is to become familiar with the data and put them in order. As a first step, I have read the material so as to understand what this data mean. Second, I have clarified the data collected in terms of the source of the data and the content of data. The data were divided, in terms of source, into two categories: data from the review of the literature review and data from interviews. The first category includes data from the review of documents and data from other sources, including scholars' writings and dictionaries. The second category includes data from officials and data from scholars. This paper mainly uses the first category to show the general situation of medical reform since 1978, and the second to pinpoint the problems and get implications as to improve efficiency of medical reform.

\section{Process of Medical Reforms since 1978 in China}

\section{8- 1984: Medical Market Reform in Gestation}

At the beginning of the reform, the national economy was on the brink of collapse, and our country was financially embarrassed and medically short. In the medical system, there were insufficient medical teams, low levels in management and medical skill, poor medical appliance, disproportionate ratio of doctors to nurses, aging of the experts and scholars, and outdated knowledge, etc. At that time, the medical reform aimed to supply more medical services and make the inner management of the medical system elastic in order to meet the needs of medical service and overcome the difficulties in seeing doctors, being hospitalized and performing operations.

In 1979, China's hygiene departments began to strengthen the medical management followed by the guidelines of focusing the whole country's work on modernization construction set up by the Third Plenary Session of the 11th Central Committee. In the same year, Qian Xinzhong, the Minister of Public Health of that time pointed out that the medical and public health departments 
should learn from enterprise management, have right to decide their expenditure, accounting, medical device purchase, personnel promotion and assessment of rewards or punishments.

Accordingly, Ministry of Health made policies to specify the work to be done, the bed required to be assigned, personnel allocation, work indicators, financial allowance, and rewards for completed task, and open new doors to multifarious medical agents. In 1980, the State Council ratified the Reports on Medicine Practice by Individuals drawn up by Ministry of Health. The policies above marked the beginning of market-oriented reform and the glimmering of medical reform.

\section{5-1992:Decentralization and Deregulation of Medical Reform}

Decision on Reform of the Economic Structure, adopted by our Party's Twelfth Central Committee gave priority to the overall economic restructuring, which meant the transition from Chinese rural communes system to rural household contract responsibility system and the extension of enterprise autonomy. Influenced by the economic restruction, decentralization and deregulation became the guiding principle of medical reform. In 1985,report on the policy issues of medical reform made by Ministry of Health symbolized that China's all-round medical system reform was launched officially, which referred to the necessity of reforms, relaxation of policies, administration streamline and delegation, fund raised by all possible means, and development of the ways to ensure medical reform smooth(Liu W. 2006).Specifically, delegation for medical departments in medical reform meant to learn management from enterprise and have rights to decide expenditure, accounting, purchase of medical appliance, personnel promotion, and rules of award or punishment (Qian XZ. 1979).In 1989, in order to ensure the delegation and give full play to the hospitals and the doctors, the State Council made five regulations: first, positively carrying forward various kinds of contract responsibility system; second, developing non-gratuitous amateur service; third, adjusting standard of health service price; fourth, launching the non-gratuitous service in the sites of preventive healthcare; fifth, carrying out "Support the Staple with the Sideline, Promote Health with Industry" in the medical system. Such multiform mechanism of responsibility as the Administrative Chiefs Responsibility, Objective Management, Post Responsibility System, More Pay for More Workand othersused in the whole medical system achieved great results. In the mechanism of finance compensation, the proportion of financial compensation was significantly reduced when the business income was increasing. In 1987, the average business income of hospitals got an increase of more than five times compared to what it had been in 1980 and the percentage in the total income of the hospitals was $73.5 \%$ in 1987 while $57.34 \%$ in 1980.National payment for average eremainder budget of the hospital decreased with years, but the percentage of the payment in the total income of the hospitals was $23.87 \%$ in 1980 while $10.18 \%$ in 1987(Zhang YM.1999).Meanwhile pharmaceutical enterprise and hospitals had rights to decide medication circulation and the price of medical appliance was fixed by the market, followed by the establishment of local pharmaceutical factories.

\section{2- 2003:Deepening of Medical Market Reform}

The deepening of medical market reform began from the early 1990s to the early 2000s. In1992, the 14th National Congress of CCP decided on socialist market economy as the goal of China's reform of economic structure. In 1995,some Important Issues Concerning the Reform and Development of the State owned Enterprises passed by the fourth Plenum of the Fifteenth CPC Central Committee meant that the reform of state owned enterprises stepped in a critical period. In 1997, the State Council of the People's Republic of China for Decision on Health Reform and Development was promulgated. In this macro environment, medical reform was actively geared to the socialist market economy. This reform included the system of medical insurance for urban workers, the public health management system, development of community health services, medical care and health operating mechanism. In September 1993,Ministry of Health issued notice torequire the medical staff to improve the consciousness of medical quality. In February 1994,Regulations of Administration in Medical Institutions regulated the planning, examining and 
approving ,registration, practicing, supervision management and related legal responsibilities, then administration of medical practice of medical institutions was brought onto the track of the legal system. However, this reform received unexpected result. Specifically, this paper concluded as follows:

(1) The implementation of tax distribution increased inequality between the developed and less developed areas, especially in the middle-west part of China in which health expense couldn't be guaranteed because of the unequal division of financial and administrative powers between the Central Government and the local governments. During ten years from 1991 to 2000, the governments increased their spend on rural health, whereas the percentage decreased from $12.5 \%$ to 6.5\%(Li HS. 2005).

(2)The reform of state-owned enterprises accounted for the establishment of basic medical insurance system for town staff. Meanwhile medical treatment was transferred from free health services and labor insurance services to socializing medical insurance.

(3)The integration of manufacturing and marketing of medicine and medical appliance was divided and medical appliance was fully maketized. In addition, the supervision system of medicine and medial appliance sustained intersected and uniform and supporting policies were absent, thus failing this reform to curb false price of the medicine and deal with the confusion of medical management in the late 1990s.

(4) Included in this reform, regional health program and classified regulation in public health departments failed to achieve the expected results.

(5) In the early 1990s, some hospitals tended to adjust and improve their internal operating mechanism, and some hospitals adopted stock system and shares by interior staff and workers(Wu M. 2004, Seminar of Medical Reform at Peking University 2006).

\section{Till Now: the Returning of Commonweal of Health Care}

Grim problems in medical system were exposed by SARS in 2003, and then aroused reflection upon China's medical policy. In addition, from SARS , the government was aware of the defects of China's health system. Therefore, with the guiding ideology of scientific development, a new reform had to be set up to emphasize the commonweal of health care and improve people's livelihood. On January 16th 2003,Suggestions on New-typed Rural Community-sponsored Medical Service System issued by the State Council marked that the government began to rebuild the system of medicaland sanitation security. Meanwhile the debate about medical marketization reforms from governments and various circles of society became fierce and they argued them erits and demerits of the past reforms. However, in July 2005,Development Research Center of State Council released a research report on healthcare reform by the media and called China's medical reforms unsuccessful as a whole because of the marketization and commercialization of medical service. In the same year, Guiding Suggestions Concerning the Deepening of Urban medical System Reform in trial units proposed by the Ministry of Health, decided on keeping the commonweal of public medical institutions as the goal of this reform.

In September 2006, the State Council founded a coordination committee for work on new medical reform, consisting of 11 commissions and ministries and explored the way of democratic decision-making to improve its quality which was also a new glowing point of this reform. On January 21st 2009,new medical reform scheme was passed in principle in the Executive Meeting of the State Council presided over by then Premier Wen who announced that the government would put 850 billion RMB in this medical reform, the aims of which were that rate of joining medical insurance for urban and rural residents increased by above $90 \%$. On April 7th 2009, Medical System Reform Scheme in Recent Practicing (2009-2011)promulgated that the new medical system should provide medical service more safe, efficient, convenient and inexpensive.

Overall, this reform included as follows:(1)Enhancing the liability of government: to increase input in public health; to improve financial transfer and payment system; (2)Improving the ability of medical service in rural areas;(3)Developing the commune medical service;(4) Popularizing 
new-type rural cooperative medical service and basic medical insurance for urban residents;(5)Strengthening management of medicine production and circulation.(6)Reinforcing the construction of medical ethics.

\section{Overview of the Medical Reforms over the 30 Years after 1978}

\section{Achievements of the Reforms}

Firstly, effective control of the infectious diseases. Based on the principle of putting prevention first, especially after SARS, China has set up the largest public health system since the founding of new China, which means to establish a fully functioning system for disease prevention and control, for emergency medical aid and for health inspection and supervision that covers both urban and rural areas. Meanwhile, China also provide free medical treatment for patients of AIDS, tuberculosis, schistosomiasis or other serious infectious diseases and immunization program and 15 vaccinations against infectious diseases for free.

Secondly, the establishment of medical insurance system that covers both urban and rural areas. Basic medical insurance system for staff members and workers, basic medical insurance for urban residents and new rural cooperative medical system account for the basic medical insurance system of social insurance nature that covers more than 200 million urban employees, more than 100 million urban residents and 800 million rural residents. In addition, China has improved medical aid system in urban and rural areas and vigorously perfected medical insurance and commercial health insurance in order to meet diversified demands from different groups.

Thirdly, the establishment of better medical service system. From 1978 to 2007, China's medical institutions increased from 170 thousand to 298 thousand including 19.852 thousand hospitals and 39.876 thousand township health centers. Hospital beds grew from 2.04million to 3.70 million and medical workers from 3.10 million to 5.90 million. Besides, there were 614 thousand village clinics and 882 thousand rural doctors .Moreover, medical service quality and expertise has improved significantly, when strengthening the management of medical institutions.

Fourthly, the improvement of the system of medical production, circulation and supervision. From 1978 to 2006, medical industrial output had risen by annual average increase rate of $16.1 \%$. There were about 120 thousand pharmaceutical enterprises that guaranteed medical service for people. Besides, 2.7 thousand institutions of food and drug administration, a thousand technology institutes and 64 thousand supervisors ensured safety and effect in medication.

Fifthly, the growing of fitness of the whole population. The infant mortality rate in 1981 was approximately 40 per 1000 . In the1990sit had fallen to 31 per 1000 (Sheila H.\&Jie S.1996). And average life expectancy remained at 69years for men and 71 for women(Green paper of health care2006).Till 2008 average life expectancy was at 73 years, and infant mortality and maternal mortality rate fell by $63.9 \%$ and $57.1 \%$ respectively.

\section{Problems Existing in the Medical Reforms}

Medical reform is a universal problem. In China, we've got some achievements in medical reforms, but we should know clearly that after the reforms, some problems haven't been resolved, and more serious problems arise. Here, this paper concluded the problems as follows:

(1) Overly expensive medical service

In 2003, the Third National Health Service Survey made by the Ministry of Health showed that the percentage of patients without physician contact increased from $36.4 \%$ in 1993 to $48.9 \%$ in 2003 and patients in need for hospitalization without being hospitalized was $29.6 \%$. Besides, $60 \%$ of hospitalized patients offered to be discharged from hospital because they couldn't afford to pay for the treatment. In rural areas, the rate of patients in need for hospitalization without being hospitalized grew from $63.7 \%$ in 1998 to $75.4 \%$ in 2003. Many people, especially peasants were reduced to the poor due to illness. The following reasons accounted for this phenomenon. Firstly, rapidly growing medical expenditure; secondly, high rate of medical treatment charge of individual 
responsibility; thirdly, false high prices and poor commonweal.

(2) Difficulty of seeing doctors

Firstly, distribution of health expenditure, health infrastructures and human resources tend to flow to the urban areas. China's $80 \%$ of medical resources concentrate in the big cities that share $20 \%$ of population, with $20 \%$ of medical resources in rural areas that were occupied by $80 \%$ of population (Zhou Y. 2006). From 1990 to 2000, the government allocated from 4.87 billion yuan to 15.116 billion yuan for rural health, but the rate in government finance expenditure decreased from $1.44 \%$ to $0.69 \%$ (Chinese National Health Ministry 1998).

Secondly, great differences between the regions. Owing to the uneven development of regional economies, the central and west regions, particularly the latter, now, in general, lag behind the coastal areas in east China. So do the development of medical service. In 1997, there were 16,195 thousand institutions in Guangdong with 305,643 medical servants, but 895 in Guizhou with 101,588 medical servants.

Thirdly, unequal distribution of medical resources in the classified medical institutions. In the late 1980s and early 1990s, China conceived of hospitals being stratified, which meant large hospitals were responsible for difficult and complicated cases while small hospitals for outpatient service. But this plan failed because the medical institutions of low level, comprehensive hospitals and special hospitals were unreasonably stratified and divided in labor so that high technology, well appliance and talents in medical system flew to the large hospitals, especially those in big cities.

(3) Inadequate medical insurance system

Firstly, single way of medical insurance. The government takes more direct responsibility for medical insurance, the stratification of which is not scientific. In addition, the government has not effectively managed the affairs of medical insurance. Commercial health insurance is hard to involve in the health insurance, and now there are only about 20 institutions with no more than 20 million customers. Secondly, poor connection of systems. Various rules and regulations concerning medical insurance, due to different management departments, different time of coming on, low level of overall design and poor overall consideration, haven't strengthened the connection between insurance group, insurance method, insurance treatment and administrative service. Thirdly low level of medical insurance. In 2006,theproportion of claims of new-type rural cooperative medical service was about $35 \%$, and although medical aid was put into practice, the level still remained low.

(4) Medicine manufacturing and circulation system in disorder

In China, the enterprises about medicine manufacturing and circulation are characterized by large quantity and small scale and the relevant government agencies don't conduct effective supervision over these enterprises. Up to the end of 2006, there were 5,000 medicine manufacturing enterprises, of which 3,731 were approved by Good Manufacturing Practice(GMP) and the rest not. And there were 12,000 wholesale enterprises and 120,000 retailer enterprises. China has a large number of enterprises which meant supply exceeded demand and the price of medicine should drop, but the price, in turn, was increasing and expensive medicine sold well.

(5)Offside and absence of central government function

Since 1998, medical system has abided by two principles which were market mechanism and government leading. However, market is not omnificent. For a long time, owing to imprecise governmental medical function positioning and unclear administrative responsibility, the development of health care industry was not compatible with requirements of a socialist market economic structure, but also the people's growing health needs, medical policy and aims of medical reforms did not match well. Firstly, the offside of government function. In the medical field, offside means that the Government makes much more direct supervision and administrative intervention on business activity of public medical institutions. During the phase of deepening of medical market reform, the Government didn't reduce the intervention on medical system but the financial investment by the Government dropped. So, the Government still plays a leading role. The Government, as an owner of hospitals, when fulfilling their duties of planning, supervision and inspection, intervenes in microscopic business activity. It indicates that the Government has the 
right to manage, plan, supervise and partially run the hospitals, and it acts strange roles that are supervisor and supervisee, and both regulator and by-regulator, like the referee and athlete, thus perplexing the Government between social management function and the operation of state-owned assets and making it afford many affairs that are not easy to deal(Hao M., Chen JL., et al.2004). From the analysis above, this governmental management no longer meets the people' need of medical service. Secondly, absence of government function. Absence means government hasn't performed its function. In medical field, it is the absence of medical supervision system that includes the supervision of medical institution, medical service practice and medicine market. In China, health care is a kind of social welfare service, and hospital is the main provider of such service. It is the governments to ensure the demand of medical service. However, most of the public medical institutions pursue economic interests as the private hospitals do and they totally give up the aim of commonweal. On China 2005 Health Top Forum, some experts pointed out that over 95\% of public hospitals ran by the way of business model. Then this model is negligent of commonweal and leads low income people and peasants not to afford to see doctors. Facing out this situation, government is absent. In addition, supervision of medicine circulation is also important. Nowadays, China's circulation of medicine and medical appliances are in disorder, where medicine price is falsely high and fake and substandard medicines become a scourge. These phenomena are closely interrelated to governmental supervision. So it is essential for government to further strengthen supervision and control over the medicine circulation.

\section{Discussion}

The following practical implications can be gained from the above findings:

(1) Rationalizing the relations between the government and market

It is commonly identified that the government, as a leading role in the medical service, undertakes the commonweal of medical service that does not exclude market function. Marketization is not the cause of high charges from medical institutions but the unreasonable pricing and medical service(Ding QY. 2009). So, China needs both government leading role and market function to provide people medical service of diversification and multi-level. It is indispensable for government and market to take clear-cut responsibilities, which are performed in accordance with properties of different medical service. Specifically, public hospitals need more financial support from government; on social medical insurance, government should play a leading role with social participation; market functions an important role in medicine production and circulation, and private institutions and commercial health insurance under governmental guidance and supervision; Government provides basic medical insurance for such particular groups as the poor, the old and the disabled, etc.

Besides, there exists government failure and market failure, which is the main cause of failure of medical reforms. So medical policy should give rein to government, market and society and set up a multi-channel and an open policy network.

(2)Increasing government function

Firstly, to raise funding for medical system. Medical system is very complex, including medical institutions, patients, insurance agencies and medicine providers, all of which are the object of medical reform. There are two parties for government. One is supplier party and the other is demanding party. For the former, medical institutions are encouraged to develop low or free medical service, which is characterized by fairness without any intermediate cost. For the latter, medical insurance is joined by the way that government pays for insurance premium instead of individuals. From the analysis above, government should increase investment for both parties. Meanwhile, the investment should vary with different areas and multi-dimensional measures are required to perform medical reforms.

Secondly, perfecting legislation and strengthening law enforcement

Strengthening legislative constructionis important for medical reform. In China, although a series 
of policies and medical regulations have already been carried out, investigation and prosecution for illegal activity are not adequate. In addition, confronting medical disputes, medical institutions need law-executive organs deal with the extreme events between hospitals and doctors.

Thirdly, strengthening governmental supervision and control

In China's medical field, for government, one of its core roles is to supervise and ensure medical service quality and safety(Gao SJ.,Zhang AX.et al.2006). Government can take several measures to act its supervising role. Policy guide is the first way for government to perform supervisory duties. As for the present medical reform, it may not immediately meet the needs of medical servants and patients, moreover harm the group or individual interests. So the government should take efforts to raise people's consciousness and clearly define governmental supervision duty. Owing to information asymmetry in medical market, market regulation policy is necessary for government to strengthen its administrative interference and macro-management for medicine circulation, hospital operation and medical insurance.

\section{Promoting Basic Medical Insurance System}

Based on China's actual conditions, we can exert efforts from the following aspects(People's Government of Hunan province2009): first of all, steadily to expand coverage of basic medical insurance. This insurance system consists of medical insurance for urban workers, urban residents and new rural cooperative medical system), coverage of which should increase respectively to $90 \%$ or more; secondly, to raise the standard of basic medical insurance; thirdly, to standardize fund management of the basic medical insurance; fourthly, to improve the medical aid system; fifthly, to popularizeone card to directly connect medical insurance institutions to the appointed medical organizations. Sixthly, to accelerate informatization construction of medical insurance and gradually realize the coordination between medical insurance and appointed medical organizations. Financial departments at all levels should arrange their expenditures to develop management software of all kinds of basic medical insurance as to set up an insurance network and comprehensive settlement centers.

\section{Reforming Medical Service System}

Now, there are three levels in China's medical service system and its structure seems to be an "inverse triangle" which means large hospitals pool patients while medical institutions at low levels shrink, thus wasting resources and incurring high expense. We can combine first-level and second-level institutions into one level, and two levels leave to resolve the problem of "inverse triangle" and increase efficiency of health systems. Here, this paper concludes three key points to reform medical service system.

Firstly, to reform the medical management system and operation mechanism.

Medicine abuse and its price out of control make up the high medical cost. Currently, China's medicine sale depends mainly on prescription by doctors in the hospital pharmacy and doctor's income is closely linked to medical service revenue which results in irrational medicine-use and examination-doing. This phenomenon is called conspiracy of doctor and medicine. Breaking this conspiracy and controlling the medical expense are important for reforming operation mechanism and pushing forward separation of prescribing and dispensing(Liu YL 2007). Two ways are conductive to achieveit, and one is to limit the proportion of hospital's revenue and rationalize medicine price to promote separation of prescribing and dispensing, the other to strictly practice price limitation and punishment tool. Secondly, to perfect the medical service system from communities and hospitals. Community medical service should be defined as a carrier for free institution of national basic public service, social medical aid and basic medical service to provide the basic and affordable medical service which embodies the justice of society. Community medical service should be financially input to speed up infrastructure construction and try to change the way of governmental provision and put forward a sustainable community medical system. Organizations can make profit by selling its medical resource to government so as to allocate medical resources 
efficiently. Meanwhile, community medical organizations should collaborated with other hospitals to promote medical service classified in different levels and bidirectional referral system, which means common or minor ailments are accommodated by community service and severe illness by large hospitals. Moreover, different-level institutions should set up a cooperation mechanism. A good illustration is the city of Zhuzhou in Hunan province. Thirdly, to reform medical charging regulation. Reasonable compensatory mechanism is actively exploredto promote medical reform. When attempting to separate prescribing and dispensing and reduce the unreasonable high price of medicine, medical service price should be also adjusted, which is achieved by the concerted efforts from hygiene department and price department. A new charging regulation needs to standardizephysical examination items to control overall expenses and rationalize service charge of different medical servants.

\section{References}

[1]Liu W. (2006)Medical reform interpreted by Zhu qingsheng, the former Vice Minister of the Ministry of Health--- Evolution of medical reform for 20 years in China. Beijing Times; 03-08 (9).

[2]Qian XZ.(1979) Shift the focus of medical work to modernization. The People's Daily; 01-13(4).

[3]Zhang YM.(1999) China health course for 50 years.Beijing: the Public House ofAncient Works.

[4]Li HS.(2005) Study of medical insurancesystem in China's countryside.Beijing:Economic Scientific Publishing.133.

[5] Wu M.Path analysis of management system in public non-profit hospitals in cities.China Health Management11,646-649. (2004)

[6]Seminar of Medical Reform of China Center for Economic Research at Peking University. AReport on medical reform in Suqian of Jiangsu province (Part one).(2006)

[7]Seminar of Medical Reform of China Center for Economic Research at Peking University.AReport on medical reform in Suqian of Jiangsu province (Part two).(2006)

[8]Sheila H.\&Jie S. Health care systems in transition: People'sRepublic of ChinaPart I: An overview of China's health caresystem, Journal of Public Health MedicineVol. 18, No. 3, pp. 258-265.(1996)

[9]Green paper of health care-development report of China's health care.Beijing: Social Sciences Academic Press.(2006)

[10]Zhou Y.Probe into public health care influenced by financial input. Truth Seeking2,185.(2006)

[11]Ding QY.On the problems to be handled rightly in China's medical system reform.Chinese Health Economics,11.(2009) 